\title{
Experimental Investigation of Brazilian 14-X B Hypersonic Scramjet Aerospace Vehicle
}

\author{
João Felipe de Araujo Martos, ${ }^{1}$ Israel da Silveira Rêgo, ${ }^{2}$ Sergio Nicholas Pachon Laiton, ${ }^{1}$ \\ Bruno Coelho Lima, ${ }^{1}$ Felipe Jean Costa, ${ }^{1}$ and Paulo Gilberto de Paula Toro ${ }^{2}$ \\ ${ }^{1}$ Instituto Tecnológico de Aeronáutica, Praça Marechal Eduardo Gomes, No. 50, Vila das Acácias, \\ 12.228-900 São José dos Campos, SP, Brazil \\ ${ }^{2}$ Instituto de Estudos Avançados, Trevo Coronel Aviador José Alberto Albano do Amarante, No. 1 Putim, \\ 12.228-001 São José dos Campos, SP, Brazil
}

Correspondence should be addressed to João Felipe de Araujo Martos; joaomartos@gmail.com

Received 7 February 2017; Accepted 30 March 2017; Published 2 May 2017

Academic Editor: Linda L. Vahala

Copyright (C) 2017 João Felipe de Araujo Martos et al. This is an open access article distributed under the Creative Commons Attribution License, which permits unrestricted use, distribution, and reproduction in any medium, provided the original work is properly cited.

\begin{abstract}
The Brazilian hypersonic scramjet aerospace vehicle 14-X B is a technological demonstrator of a hypersonic airbreathing propulsion system based on the supersonic combustion (scramjet) to be tested in flight into the Earth's atmosphere at an altitude of $30 \mathrm{~km}$ and Mach number 7. The 14-X B has been designed at the Prof. Henry T. Nagamatsu Laboratory of Aerothermodynamics and Hypersonics, Institute for Advanced Studies (IEAv), Brazil. The IEAv T3 Hypersonic Shock Tunnel is a ground-test facility able to produce high Mach number and high enthalpy flows in the test section close to those encountered during the flight of the 14 -X $\mathrm{B}$ into the Earth's atmosphere at hypersonic flight speeds. A $1 \mathrm{~m}$ long stainless steel 14-X B model was experimentally investigated at T3 Hypersonic Shock Tunnel, for freestream Mach numbers ranging from 7 to 8 . Static pressure measurements along the lower surface of the 14-X B, as well as high-speed Schlieren photographs taken from the $5.5^{\circ}$ leading edge and the $14.5^{\circ}$ deflection compression ramp, provided experimental data. Experimental data was compared to the analytical theoretical solutions and the computational fluid dynamics (CFD) simulations, showing good qualitative agreement and in consequence demonstrating the importance of these methods in the project of the 14-X B hypersonic scramjet aerospace vehicle.
\end{abstract}

\section{Introduction}

A new era of hypersonic flight started, in August 1963, when Robert M. White flew the rocket-powered North American $\mathrm{X}-15$, at $2020.6 \mathrm{~m} / \mathrm{s}$, corresponding to a flight Mach number of 6.7, at an altitude of $108 \mathrm{~km}$ [1]. Since then, a significant amount of research and development has been conducted worldwide into high-speed combustion and propulsion systems [2].

In 2007, Prof. Henry T. Nagamatsu Laboratory of Aerothermodynamics and Hypersonics at the Institute for Advanced Studies (IEAv), Brazil, began to research and develop a hypersonic waverider with airframe-integrated scramjet engine as an option to space access in the near future $[3,4]$, as shown in Figure 1.
Today, the Brazilian Air Force High Command has considered the $14-\mathrm{X}$ project as strategic to Brazil's sovereignty.

Inspired by HyShot [5], X-43 [6-9], and X-51 [10] programs that demonstrated the operation of scramjet engines with planar configuration, new versions of the $14-\mathrm{X}$ waverider were then designed to operate into the stratosphere at flight Mach number 7 such as the 14-X B [11, 12] (planar configuration of the 14-X waverider) and the 14-X S (mirrorimage of the 14-X B with respect to its symmetry axis), as shown in Figure 2.

In whatever 14-X configuration, the Brazilian solid boosters S31 and S30 should assist them with lift-off from one of the Brazilian Launch Centers to their operational flight conditions. 


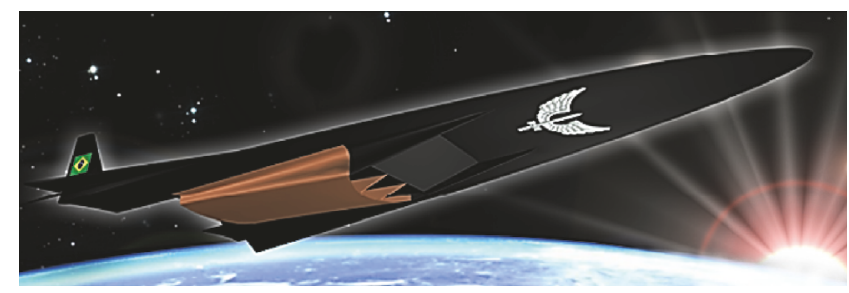

FIGURE 1: Artistic view of the 14-X scramjet-powered waverider.

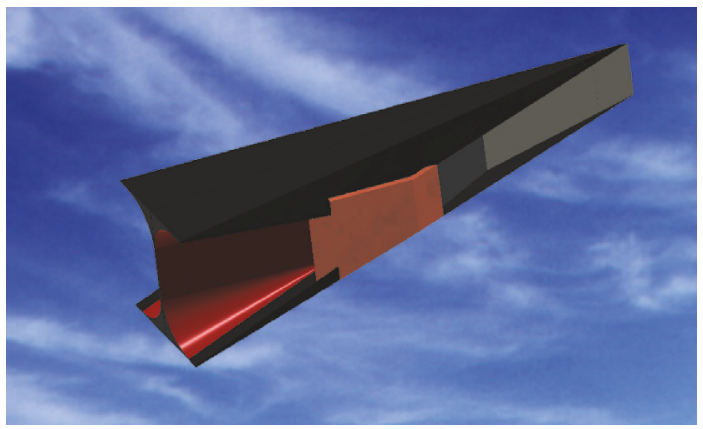

(a)

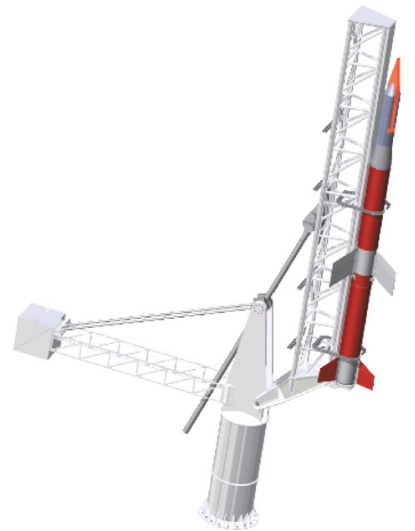

(b)

FIGURE 2: Conceptual design of the 14-X B scramjet-powered vehicle (a) and the 14-X S scramjet-powered propulsion stage (b).

Now, referring to scramjet inlets, it is well known that the number of ramps (blends) is directly related to system performance in terms of total pressure recovery and complexity in terms of machining and costs. The HyShot compression system used only one ramp [5], while the X-51 [10] used three ramps to achieve the designated conditions for combustion. In this sense, the 14-X B inlet is quite unique because it consists of two ramps only and a flat cowl, resulting in two oblique and one reflected shock wave in a way that the airflow speed and temperature expected at the entrance of combustion chamber are supersonic and above the flash point of hydrogen for self-ignition, respectively.

Despite the optimistic tone above, this paper shows the shock tunnel investigations on the internal airflow characteristics of the 14-X B version operating at around an altitude of $30 \mathrm{~km}$ and freestream Mach number near to 7. In addition, theoretical calculations and computational fluid dynamics simulations of such an internal airflow are presented.

\section{Experimental Apparatus}

2.1. Hypersonic Shock Tunnel Facility. The T3 $0.60 \mathrm{~m}$ nozzle exit diameter Reflected Hypersonic Shock Tunnel is a new Hypersonic High Enthalpy Real Gas Pulsed Reflected Shock Tunnel Facility (Figure 3) funded by São Paulo Research Foundation (FAPESP, process $n^{\circ} 2004 / 00525-7$ ), which was designed $[13,14]$ at the Prof. Henry T. Nagamatsu Laboratory of Aerothermodynamics and Hypersonics primarily as a

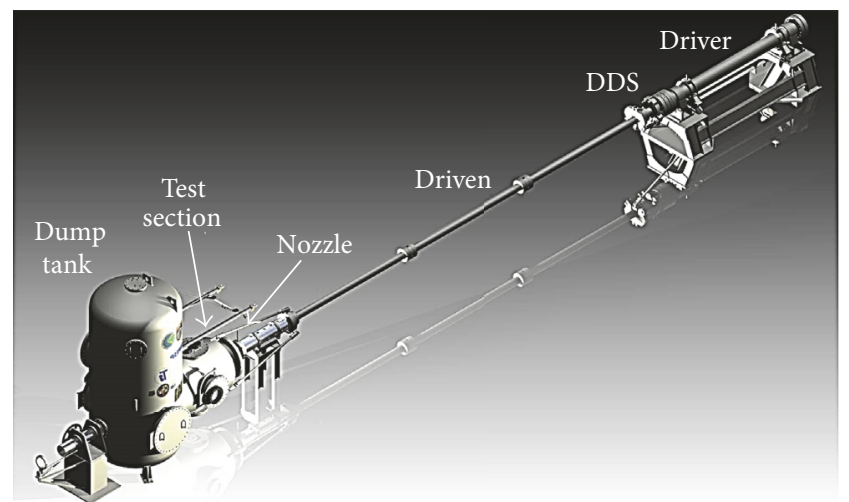

FIgURE 3: T3 $0.61 \mathrm{~m}$. nozzle exit diameter Hypersonic Shock Tunnel at IEAv.

research and development (R\&D) facility for basic investigations on supersonic combustion applied to high-speed advanced airbreathing propulsion.

The simplest Reflected Hypersonic Shock Tunnel is a shock tube equipped with a convergent-divergent nozzle to produce high Mach number and high enthalpy flows in the test section close to those encountered during the atmospheric flight of the 14-X B at hypervelocity. The basic hypersonic shock tunnel consists of a high-pressure section (driver) and a low-pressure section (driven) separated from each other by a double diaphragm system (DDS), a convergent-divergent nozzle and its diaphragm (placed at the 


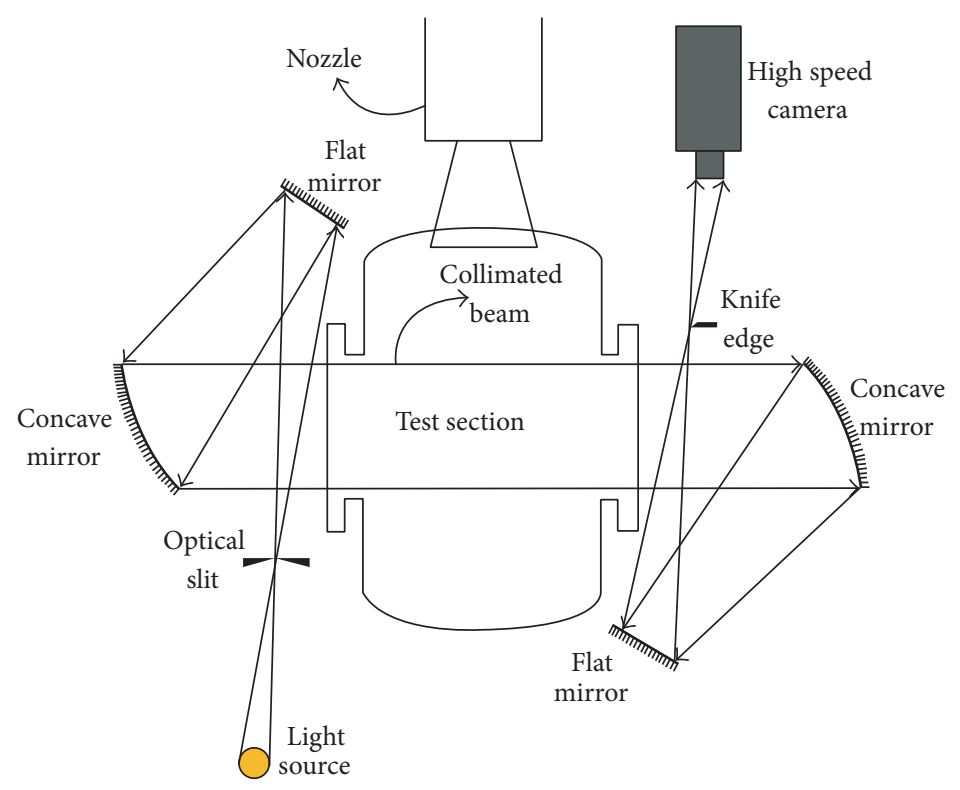

FIgURE 4: Schlieren visualization and high-speed camera system setup.

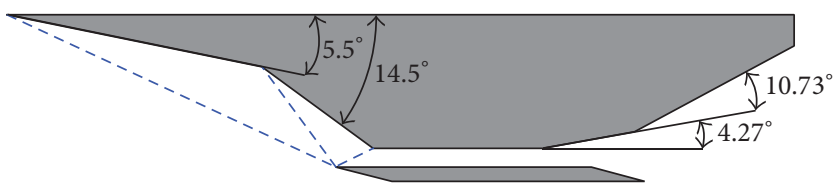

Figure 5: Cross section of the 14-X B hypersonic scramjet aerospace vehicle.

end of the driven section), and a test section terminated by a large dump tank [15].

The T3 Hypersonic Shock Tunnel was designed [14] to be operated in the 6-25 flight Mach number range, generating reservoir enthalpies in excess of $10 \mathrm{MJ} / \mathrm{kg}$ and reservoir pressures up to $25 \mathrm{MPa}$ when operated in the equilibriuminterface mode, with estimated useful test time up to $10 \mathrm{~ms}$. These conditions are estimated based on the driver-to-driven area ratio of 2.25 , on the driven length equal to 100 times the driven internal diameter $(127 \mathrm{~mm})$, and on the operating driver pressure of 5000 psi.

The T3 Hypersonic Shock Tunnel is capable of generating both high and low enthalpy hypersonic flow conditions. In the present investigation for high enthalpy runs, helium is used as the driver gas and the tunnel operates in the equilibrium-interface condition to produce a useful test time of roughly $2 \mathrm{~ms}$. The test section airflow Mach number is about 7 to 8 , while pressure and temperature are similar to those encountered in $28 \mathrm{~km}$, when in the high enthalpy operation mode [16].

2.2. Instrumentation. A high-speed camera Phantom V411, coupled with a Schlieren optical system in " $z$ " configuration (Figure 4), has been used for slow-motion visualization of the hypersonic flow. The Schlieren system is composed of a LED as light source, an optical slit and focusing lens, two parabolic and three flat mirrors, and a knife edge. The Phantom camera was set to acquire 43,329 frames per second (fps) with a resolution of $368 \times 200$ pixels, recording during the entire test time.

A multichannel oscillography is utilized to synchronize both data acquisition system and Schlieren system within the useful shock tunnel test time. The scope unit was triggered by a piezoelectric pressure transducer located immediately upstream of the nozzle entrance. Also, this pressure transducer reads the reservoir pressure before expansion along the nozzle.

Two other pressure transducers, located $0.314 \mathrm{~m}$ apart close to the end of the driven section and mounted flush with the inner wall of the shock tube end (heavy section), were utilized to time the passage of the incident shock wave.

2.3. 14-X B Test Model Design. For experimental investigation in T3 Hypersonic Shock Tunnel, the 14-X B model was scaled based on the 14-X S hypersonic scramjet aerospace vehicle design for flight at Mach number 7 and an altitude of $30 \mathrm{~km}$. The $14-\mathrm{X} \mathrm{B}$ (Figure 5) consists of a twodimensional configuration, with a constant cross section, where the upper flat surface, with zero angle of attack, is aligned with the freestream Mach number 7 hypersonic airflow. The double ramp scramjet inlet represents a forebody external compression region followed by a small region of internal compression. This mixed compression configuration can balance the problems of high external drag in the case 
TABLE 1: Thermodynamic properties of the airflow field along the 14-X B model lower surface, considering power-off case, inviscid flow, and $\gamma=1.4[11]$.

\begin{tabular}{lccccccc}
\hline Quantity & Unit & Inlet entrance & 1st ramp & 2nd ramp & Combustor entrance & Internal expansion surface & External expansion surface \\
\hline$M_{\text {in }}$ & & 7.00 & 7.00 & 6.02 & 4.06 & 2.60 & 2.79 \\
$\theta_{\text {in }}$ & $\circ$ & & 5.50 & 14.50 & 20.00 & 4.27 & 10.73 \\
$\beta_{\text {out }}$ & $\circ$ & & 12.24 & 22.11 & 32.24 & & \\
$M_{\text {out }}$ & & & 6.02 & 4.06 & 2.60 & 2.79 & 3.37 \\
$T_{\text {out }}$ & $\mathrm{K}$ & 226.50 & 296.75 & 568.46 & $1,039.72$ & 953.45 & 747.17 \\
$p_{\text {out }}$ & $\mathrm{Pa}$ & $1,197.00$ & $2,877.57$ & $16,755.80$ & $89,105.97$ & $65,803.41$ & 0.2405 \\
$\rho_{\text {out }}$ & $\mathrm{kg} / \mathrm{m}^{3}$ & 0.0184 & 0.0338 & 0.1027 & 0.2986 & 620.17 & 0.1308 \\
$a_{\text {out }}$ & $\mathrm{m} / \mathrm{s}$ & 301.70 & 345.98 & 478.87 & 647.63 & $1,735.30$ & 549.05 \\
$u_{\text {out }}$ & $\mathrm{m} / \mathrm{s}$ & $2,111.90$ & $2,082.41$ & $1,946.38$ & $1,684.62$ & $1,851.13$ \\
\hline
\end{tabular}

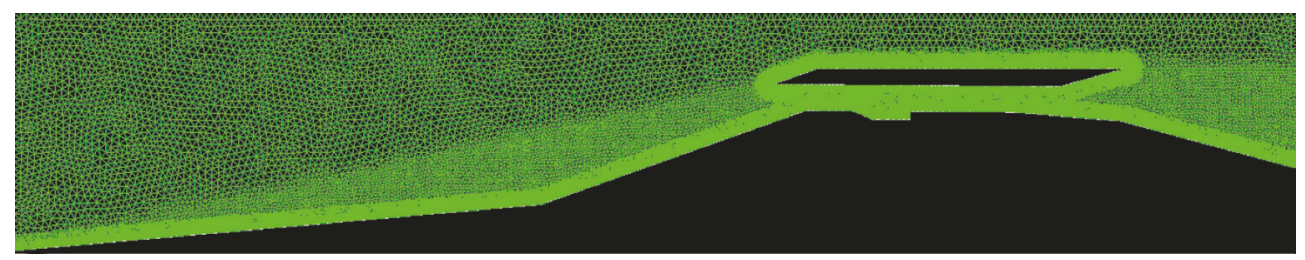

(a)

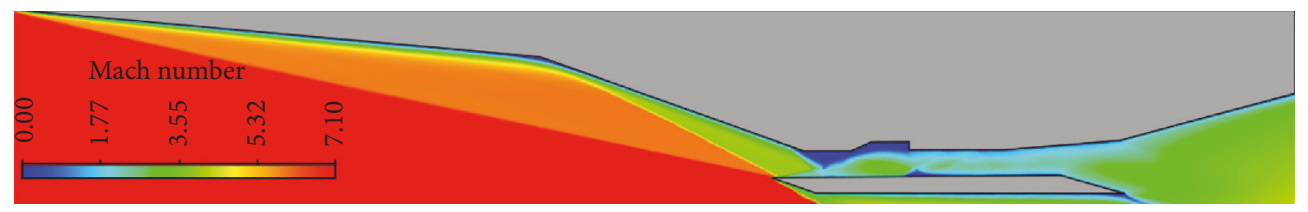

(b)

FIGURE 6: Domain and mesh used on CFD simulation (a) and Mach distribution for flight at Mach 7 (b).

of full external compression and excessive viscous effects during full internal compression. The optimal cowl inlet configuration is the well-known "shock-on-lip" condition shown in Figure 5 [17].

The lower surface consists of a frontal surface with a leading edge angle of $5.5^{\circ}$, a compression ramp with an angle of $14.5^{\circ}$ (related to the angle of the leading edge), an expansion combustion chamber with an angle of $4.27^{\circ}$, and an external expansion surface with an angle of $10.73^{\circ}$ (related to the angle of the inner expansion).

The combustor chamber has constant area and is long enough to optimize the combustion, followed by a slope of $4.27^{\circ}$ (to accommodate the boundary layer and expansion due to $\mathrm{H}_{2}$ and $\mathrm{O}_{2}$ combustion). The combustion chamber constant area (and its height) is proportional to the airflow captured by the 14-X B frontal area to preserve the mass flow.

The 14-X B model lower surface was designed based on the two-dimensional compressible flow (oblique shock wave relationships) and expansion wave (Prandtl-Meyer theory), considering the simplest case, that is, no viscous flow, calorically perfect air $(\gamma=1.4)$, and scramjet engine with power off [11]. Also, the following restrictions were assumed: The incident shock waves generated at the $5.5^{\circ}$ leading edge and at the $14.5^{\circ}$ compression ramp hit the cowl leading edge (shock-on-lip condition). The reflected shock wave generated at the cowl leading edge hits the entrance of the combustor station (shock-on-corner condition) as shown in Figure 5. Table 1 lists the airflow properties along the 14-X B model, considering the simplifications as mentioned above.

\section{CFD Analysis}

In order to solve the system of governing equations for a highspeed compressible problem, the ANSYS Fluent disposes the density-based solver. In the density-based method, the velocity and density fields are obtained from the continuity and momentum equations, and the pressure field is obtained from the equation of state. ANSYS Fluent solves simultaneously all the integral governing equations (continuity, momentum, and energy) simultaneously. Then, additional scalars such as equations for turbulence models are solved and separated from one another.

Figure 6 shows the computational domain of the 14-X $\mathrm{B}$ studied here. The freestream conditions considered in the following simulations are the experimental ones (described below). The wall thermal conditions studied were $300 \mathrm{~K}$ uniform temperature due to the short test time available on hypersonic shock tunnel. In addition, the transitional viscous model used was the Transition SST (Fluent Code) with ideal gas that according to a previous analysis is the most suitable option for this case considering the results obtained and 


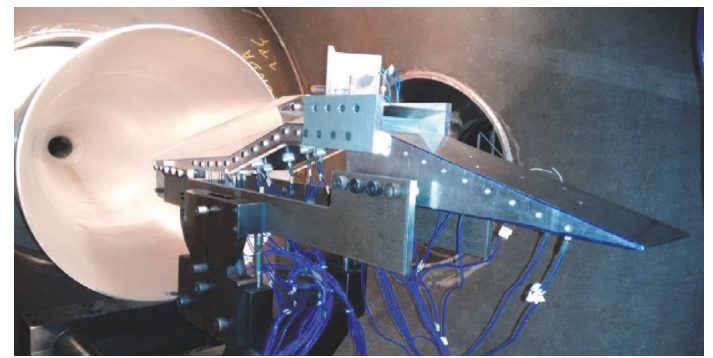

(a)

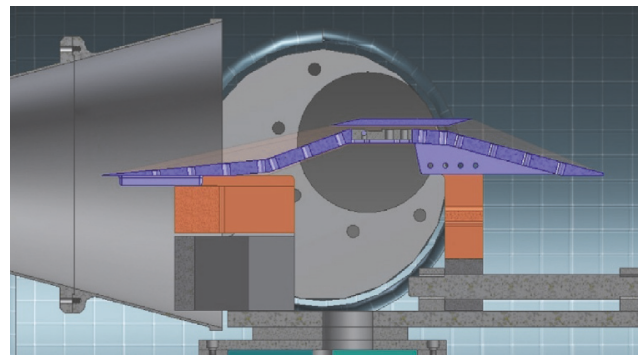

(b)

FIGURE 7: 14-X B model installed in the T3 test section: (a) Laboratory model and (b) setup of the combustion chamber entrance for flow visualization across the quartz windows.

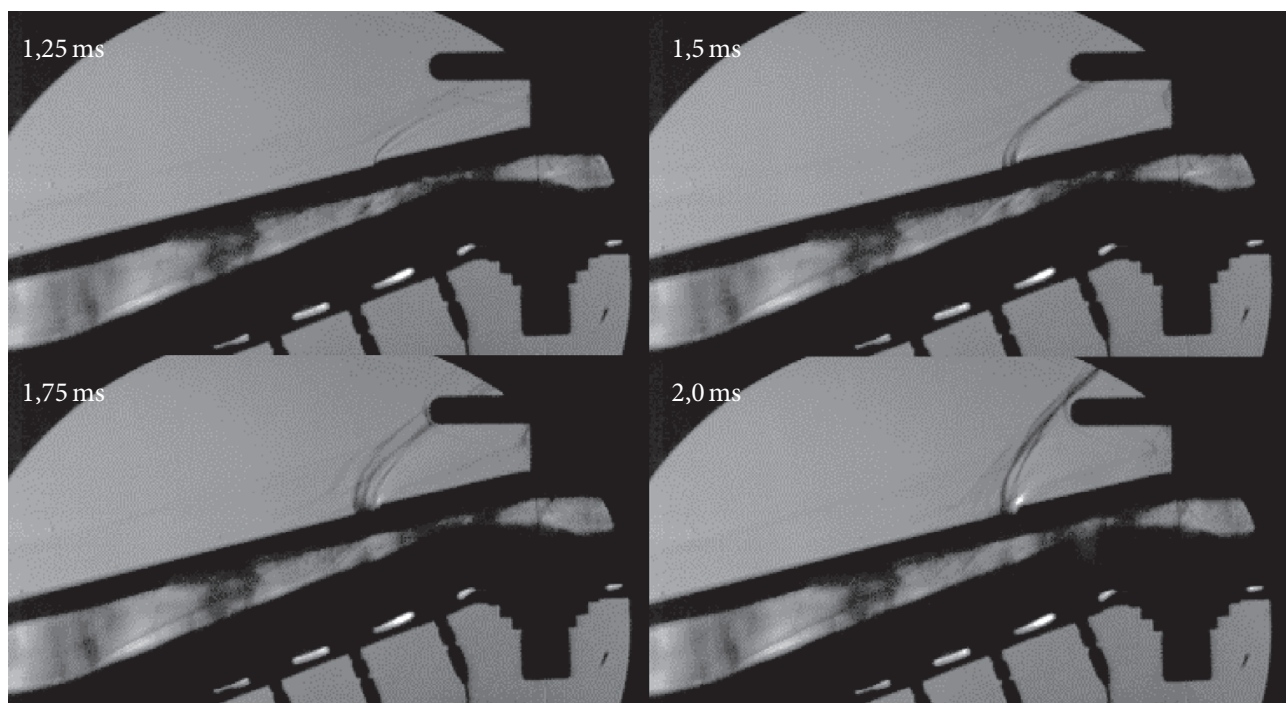

FIgURE 8: Temporal evolution of the chocked flow for ideal gas simulation.

computational power available [18]. The model used is based on the combination of the SST $k$ - $\omega$ transport equations with two other transport equations: intermittency and one for the transition onset criteria, in terms of momentum-thickness Reynolds number. The intermittency set was 1 as default by fluent, with turbulent intensity of $5 \%$ and turbulent viscosity ratio of 10 .

Meshes used had around $5 E+5$ cells being more refined near the walls in order to better calculate the physical interactions in the boundary layer and at the regions near the corner and leading edges. The mesh configuration was unstructured composed of Triangular elements. Figure 6(b) shows the mesh for the entire domain as well as Mach distribution obtained at this simulation.

\section{Experimental Results}

4.1. Flowfield Visualization over the $14-X$ B Inlet. A $1 \mathrm{~m}$ long stainless steel 14-X B model (Figure 7(a)) instrumented with twenty-nine piezoelectric pressure transducers on its lower surface was experimentally investigated in the T3 Hypersonic Shock Tunnel running at freestream Mach numbers from 7 to
8 and in the equilibrium-interface mode operation. The 14-X B model was installed on the heavy steel stands, especially designed to hold firmly the model in the T3 test section. Since the two symmetrical quartz windows utilized for the Schlieren visualization technique have their limitations as nonvariable position and useful area of visualization, the 14-X B model was positioned to optimize the visualization area for the second ramp and combustion chamber inlet (Figure 7(b)).

Fourteen runs were made, six of them using air in the driver section for perfect gas simulation and eight of them using helium in the driver section for real gas simulation. Before these, a few runs were made to identify and correct some project errors and ensure that the acquisition system was fully operational. Some problems were faced: The model had a $0.5^{\circ}$ angle of attack; blending deformation of the leading edge has occurred due to its thin thickness; and the height of combustion chamber was not enough to accommodate the viscous effects resulting in chocked flow (Figure 8).

Some modifications were made to solve these problems found such as changing the cowl position, correcting the cowl tip position and the combustor height to prevent the chocked 


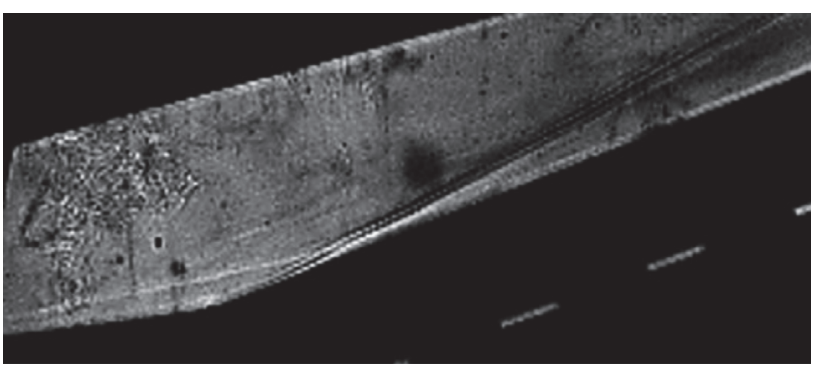

(a)

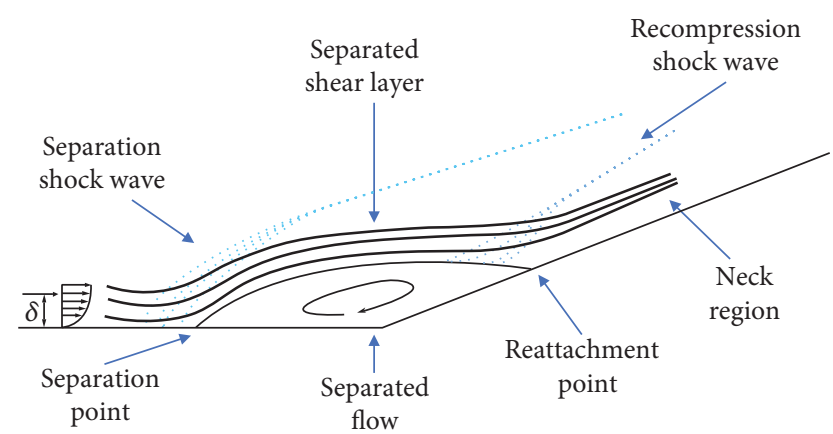

(b)

FIGURE 9: Boundary layer shock wave interaction on the 14-X B inlet (a) and flow separation scheme (b).

flow in order to ensure the shock-on-lip condition instead of the shock-on-corner condition. In the first runs (Figure 9), an interaction between the boundary layer and the shock wave between the first and second compression ramps was observed, which caused the separation of boundary layer.

According to Heiser and Pratt [19], for Mach 7 and turbulent flow, the maximum turning angle should be around $13^{\circ}$ to avoid the boundary layer separation, while for Mach 7 and laminar flow the maximum turning angle should be around $5^{\circ}$. The separation of the boundary layer is critical for a hypersonic inlet operation because it induces changes in shock wave angle and in pressure recovery as well as increments in heat transfer while it may lead to chocked flow, resulting in flow spillage and even in unstart of the engine [20]. The 14-X B model has a turning angle of $14.5^{\circ}$ between its compression ramps, such that for some experimental conditions it was possible to observe this separation.

4.2. Pressure Distribution over the 14-X B Model. As mentioned, the row of experiments was divided between the simulation of ideal and real gas. The real gas experiments simulate the flight Mach number about 7 at an altitude of approximately $30 \mathrm{~km}$ while the ideal gas only simulates the Mach number about 8 .

Figure 10 shows the pressure distribution over the $14-\mathrm{X} \mathrm{B}$ model for ideal gas condition (air in the driver section), flight Mach number $7.72 \pm 1 \%$, flow pressure of $405 \mathrm{~Pa} \pm 1.5 \%$, and flow temperature of $76 \mathrm{~K} \pm 1.5 \%$ (freestream conditions).

4.3. Verification and Validation of CFD Simulations. The static pressure measurements at the lower surface of the 14$\mathrm{X} B$ model are compared with the static pressure evaluated at the same freestream conditions via no viscous flow, calorically perfect air ( $\gamma=1.4)$ oblique shock wave relationships, and computational fluid dynamics (CFD) simulations using the ANSYS FLUENT software (Figure 9). Note that the theoretical curve does not show any oscillation in pressure into the combustor since both shock-on-lip and shock-on-corner conditions are satisfied, resulting in uniform flow.

Schlieren pictures of incident and reflected shock wave angles at flight Mach number 7.72 in perfect gas mode (air in the driver) (Figure 11(a)), emanating from the $14.5^{\circ}$ deflection

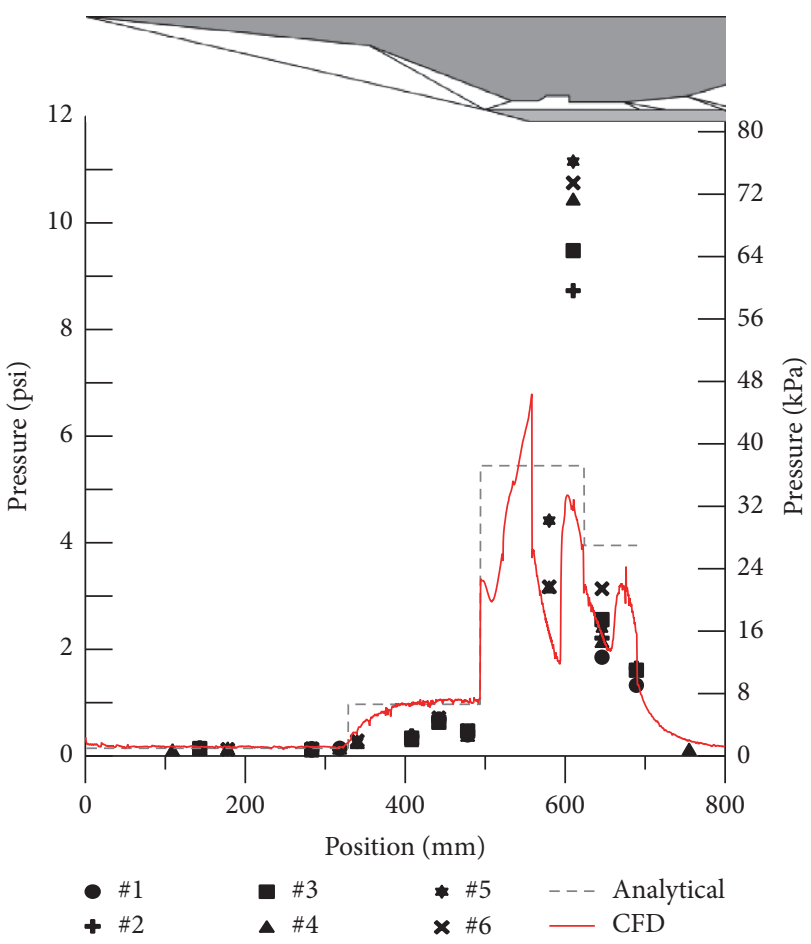

FIGURE 10: Static pressure measurements over the 14-X B model for perfect gas case (Mach number about 8 ) against theoretical solutions and CFD simulations.

ramp and reflection at the cowl of 14-X B model, are compared with the correspondent CFD simulation (Figure 11(b)). As expected, the shock waves angles obtained experimentally are in agreement with those shown in the CFD simulations (Figure 11(c)).

Figure 12 shows the pressure distribution for the experiments of the 14-X B obtained in real gas mode (helium in the driver) for flight Mach number of $7.1 \pm 1.5 \%$, flow pressure of $1818 \pm 5 \%$ (about $27 \mathrm{~km}$ in altitude), and flow temperature of $227 \pm 3,5 \%$ (about $30 \mathrm{~km}$ in altitude). The static pressure measurements (Figure 12) at the lower surface of the 14-X B model are compared with the static pressure evaluated at the same freestream conditions using no viscous 


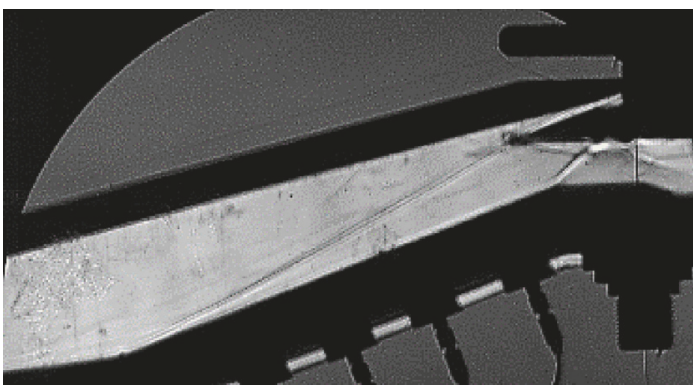

(a)

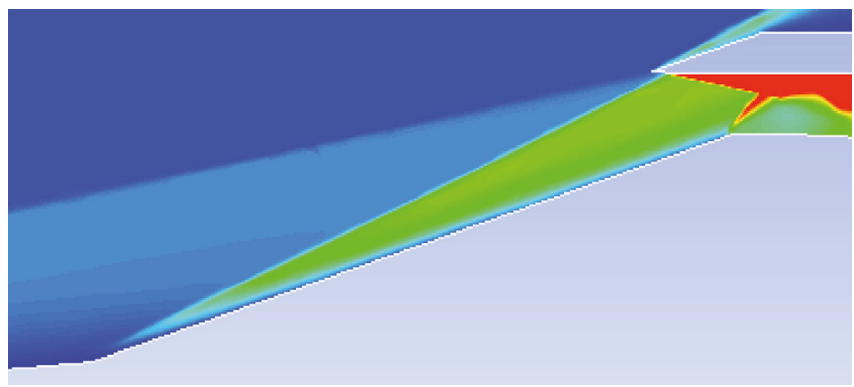

(b)

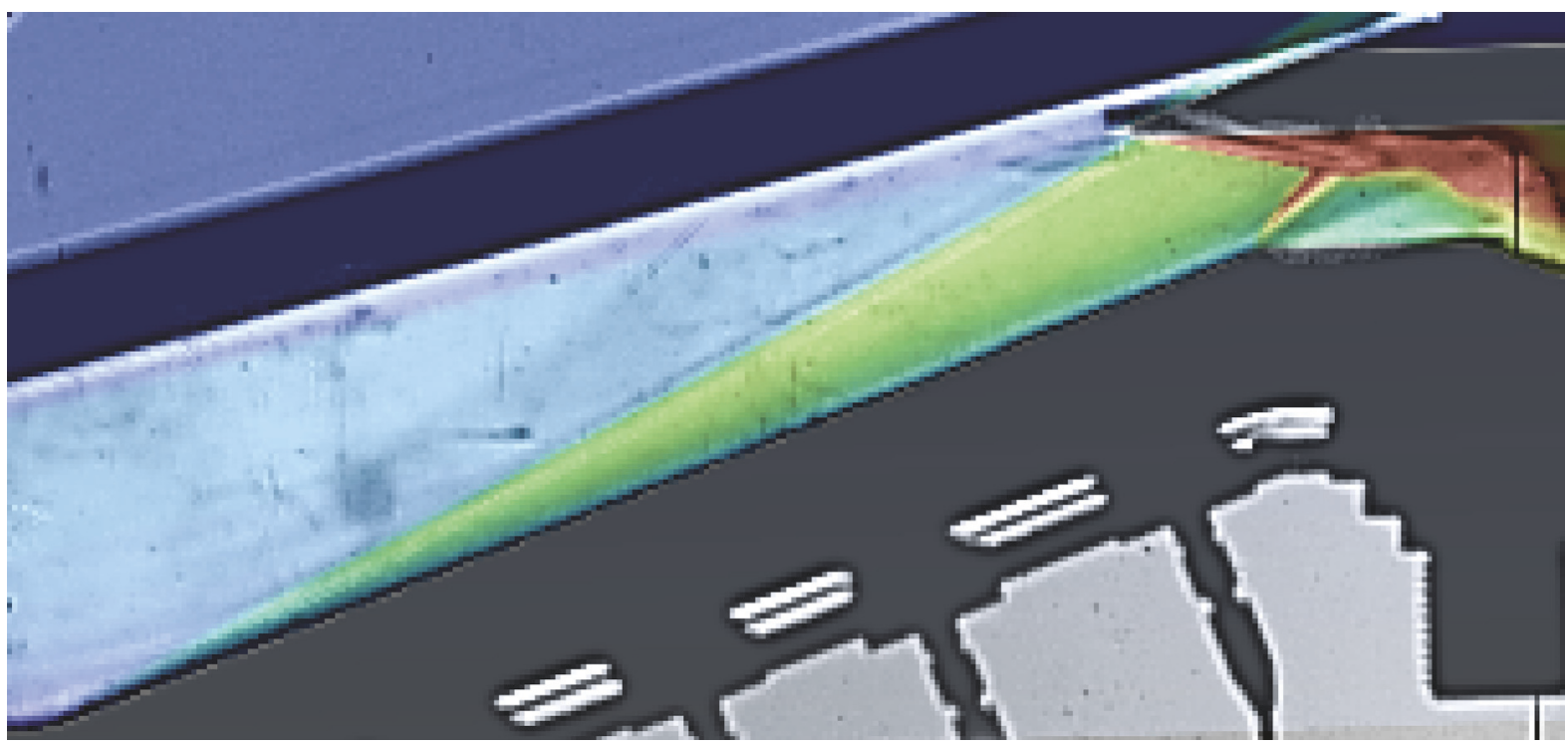

(c)

FIGURE 11: Schlieren picture of the airflow field at flight Mach number 7.725 for perfect gas mode (a); CFD simulations at same conditions; (b) comparison between Schlieren picture and density contour (c).

TABLE 2: Thermodynamic properties of the airflow field along the 14-X B model lower surface considering the freestream properties for real gas simulation, power-off case, inviscid flow, and $\gamma=1.4$.

\begin{tabular}{lccccccc}
\hline Quantity & Unit & Inlet entrance & 1st ramp & 2nd ramp & Combustor entrance & Internal expansion surface & External expansion surface \\
\hline$M_{\text {in }}$ & & 7.10 & 7.10 & 6.18 & 4.14 & 2.68 & 2.88 \\
$\theta_{\text {in }}$ & $\circ$ & & 5.00 & 14.5 & 19.5 & 4.27 & 10.73 \\
$\beta_{\text {out }}$ & $\circ$ & & 11.088 & 21.377 & 30.793 & & 3.879 \\
$M_{\text {out }}$ & & & 6.183 & 4.140 & 2.676 & 946.49 & 737.18 \\
$T_{\text {out }}$ & $\mathrm{K}$ & 227,00 & 290,92 & 568.23 & $1,034.30$ & $95,742.29$ & $39,921.56$ \\
$p_{\text {out }}$ & $\mathrm{Pa}$ & $1,818.00$ & $4,103.93$ & $24,797.37$ & $130,604.94$ & 0.3525 & 0.1887 \\
$\rho_{\text {out }}$ & $\mathrm{kg} / \mathrm{m}^{3}$ & 0.0279 & 0.0492 & 0.1521 & 0.4400 & 616.68 & 544.24 \\
$a_{\text {out }}$ & $\mathrm{m} / \mathrm{s}$ & 302.01 & 341.90 & 477.82 & 644.66 & $1,775.49$ & $1,890.20$ \\
$u_{\text {out }}$ & $\mathrm{m} / \mathrm{s}$ & $2,144.25$ & $2,114.10$ & $1,977.95$ & $1,725.10$ & & \\
\hline
\end{tabular}

flow, calorically perfect air $(\gamma=1.4)$ oblique shock wave relationships (Table 2), and computational fluid dynamics simulations using the ANSYS FLUENT software. Again, CFD simulations agree better with the experimental data when compared to analytical theoretical calculations. As expected, the pressure distributions for real gas and ideal gas simulation are similar, once the Mach numbers and the structures of shock waves are similar too.
It was considered air as calorically perfect $(\gamma=1.4)$ because the maximum temperature, along of the lower surface, of the 14-X B model at design conditions is below the dissociation temperature (Tables 1 and 2).

Schlieren pictures of the incident and reflected shock wave angles for the flight Mach number 7.1 in real gas mode (helium in the driver) are shown in Figure 13(a). The airflow field over the $14.5^{\circ}$ deflection ramp and around the 


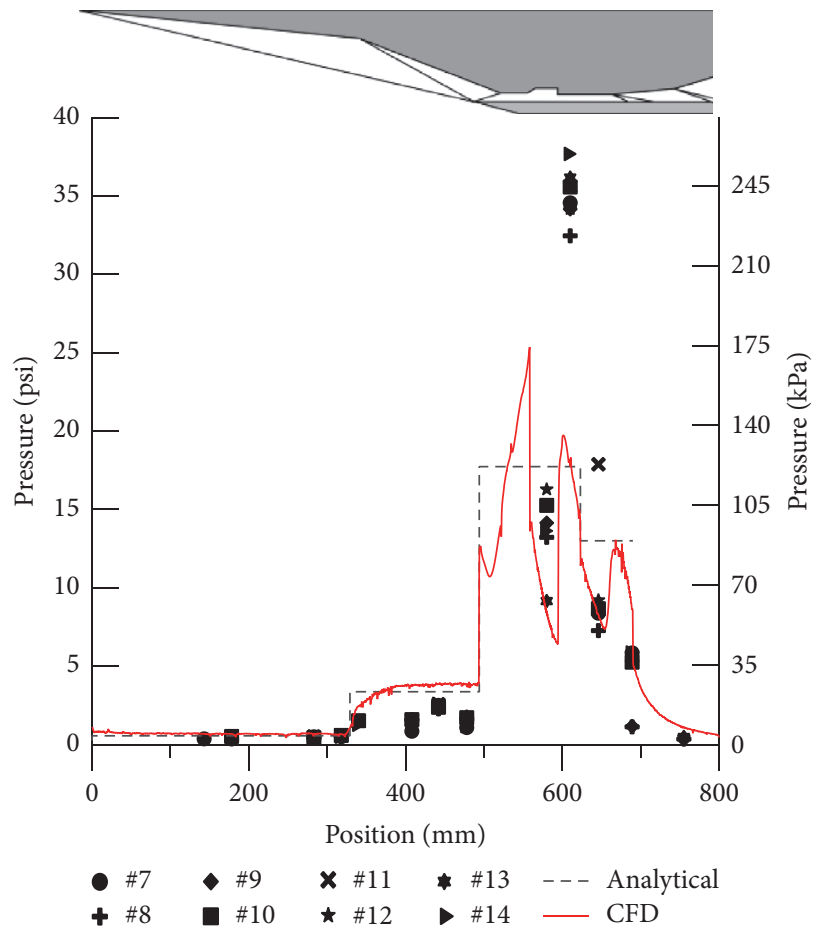

FIGURE 12: Static pressure measurement over the 14-X B model in real gas mode.

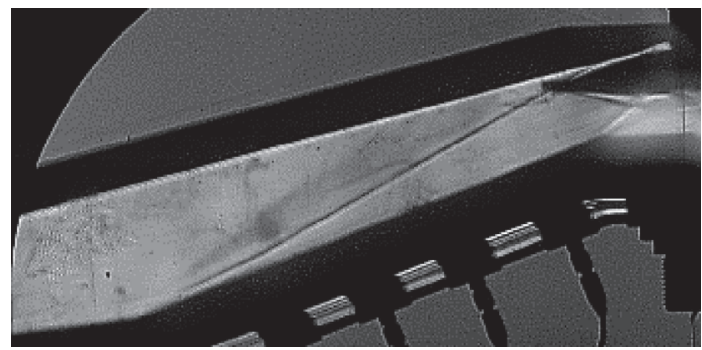

(a)

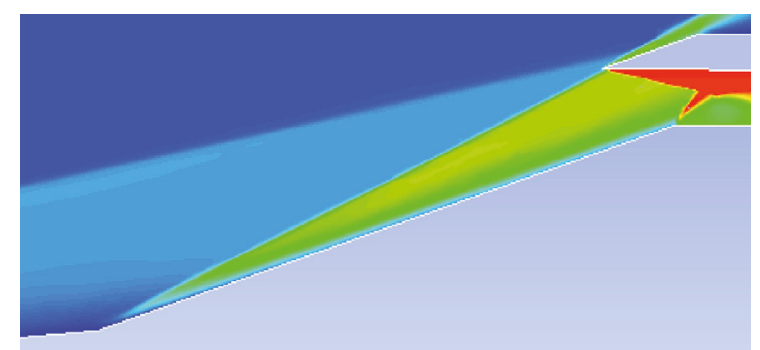

(b)

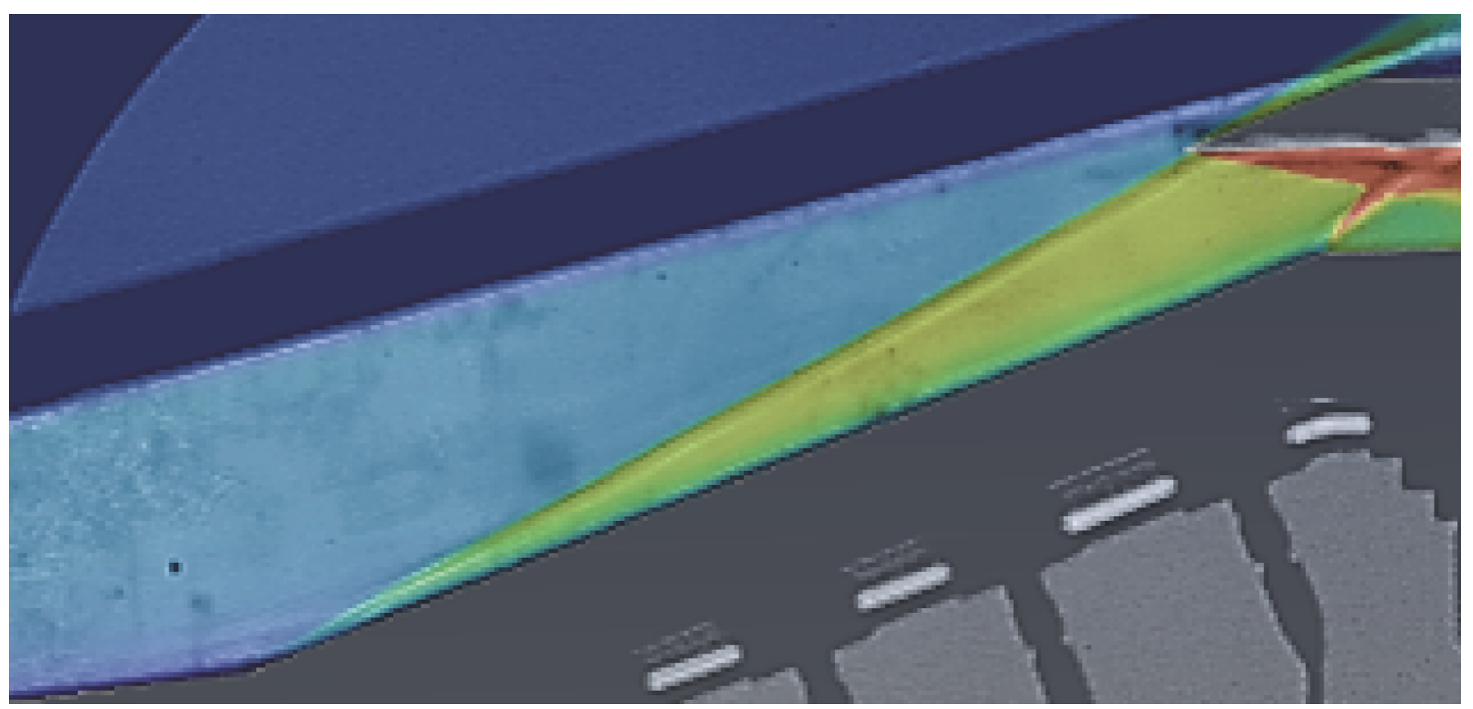

(c)

FIGURE 13: Schlieren picture of the airflow field for at flight Mach number 7.1 in real gas mode (a); CFD simulations at the same conditions; (b) comparison between Schlieren picture and density contour (c). 
of 14-X B cowl is compared with that correspondent to CFD simulations of the density variation (Figure 13(b)). As expected, the shock waves angles obtained experimentally are in good accordance with the CFD simulation (Figure 13(c)).

The results obtained are qualitatively satisfactory despite some quantitatively difference between the experimental data and the results obtained theoretically and via CFD. Once the airflow field over the 14-X B model is in good accordance with the CFD simulation, the pressure distribution should be in good accordance too, due to the hypersonic flow nature whose properties before and after a shock wave are related to its intensity. Improvements in the data acquisition system and sensors are necessary to reduce errors and better understand the gas dynamic phenomena involved during scramjet operation. The evaluation of pressure and temperature distribution at the boundary layer also are necessary because of sensor positioning.

\section{Conclusion}

An experimental investigation of the airframe-integrated scramjet 14-X B was made in the pulsed hypersonic wind tunnel T3 at IEAv. Static pressure measurements along with high-speed Schlieren photographs were utilized to investigate the hypersonic airflow field along the 14-X B model. Pressure measurements along the model were done and compared with the values calculated analytically via shock wave theory and computationally via CFD. Despite the quantitative differences, in general, the experimental and theoretical values exhibit qualitatively the same behavior, but the CFD simulations approximate better to the experimental data. High-speed Schlieren photographs compared with the CFD simulations show that the architecture of the shock waves generated over the $14-\mathrm{X} \mathrm{B}$ model is consistent with that expected for the shock-on-lip condition at flight Mach number about 7 (project condition). Therefore, these results have demonstrated the importance of matching theory, ground experiments, and computational simulations in the project of the 14-X B hypersonic vehicle before flight tests.

\section{Conflicts of Interest}

There are no conflicts of interest.

\section{Acknowledgments}

The last author would like to express gratitude to FINEP (Agreement no. 01.08.0365.00) not only for the financial support for the 14-X hypersonic aerospace vehicle design and experimental investigations but also for financial support to graduate students (period 2014-2015). Also, thanks are due to the COMAER for financial support for graduate students (period 2016).

\section{References}

[1] J. J. Bertin and R. M. Cummings, "Fifty years of hypersonics: where we've been, where we're going," Progress in Aerospace Sciences, vol. 39, no. 6-7, pp. 511-536, 2003.
[2] R. N. Kostoff and R. M. Cummings, "Highly cited literature of high-speed compressible flow research," Aerospace Science and Technology, vol. 26, no. 1, pp. 216-234, 2013.

[3] P. G. P. Toro, M. A. S. Minucci, T. C. Rolim et al., "Brazilian 14-X hypersonic aerospace vehicle project," in Proceedings of the 18th AIAA/3AF International Space Planes and Hypersonic Systems and Technologies Conference, Tours, France, 2012.

[4] M. F. F. Ricco, P. P. Funari, and A. V. Carvalho, Espaço, Tecnologia, Ambiente e Sociedade 1, Habilis Editora Erechim, vol. 8, Habilis Press Editora, RS, Brazil, 2011.

[5] A. Paull, H. Alesi, and S. Anderson, "The development of the HyShot flight program," in Proceedings of the 24th International Symposium on Shock Waves, Beijing, China, 2005.

[6] C. R. Mcclinton, D. S. Rausch, and P. Reukauf, "Hyper-X program status," in Proceedings of 10th International Space Planes and Hypersonic Systems and Technologies, Kyoto, Japan, 2001.

[7] P. L. Moses, V. L. Rausch, L. T. Nguyen, and J. R. Hill, "NASA hypersonic flight demonstrators-overview, status, and future plans," Acta Astronautica, vol. 55, no. 3-9, pp. 619-630, 2004.

[8] L. A. Marshall, G. P. Corpening, and R. Sherrill, "A chief engineer's view of the NASA X-43A scramjet flight test," in Proceedings of 3rd International Space Planes and Hypersonic Systems and Technologies Conference, Capua, Italia, 2005.

[9] L. A. Marshall, C. Bahm, G. P. Corpening, and R. Sherrill, "Overview with results and lessons learned of the X-43A mach 10 flight," in Proceedings of AIAA/CIRA 13th International Space Planes and Hypersonic Systems and Technologies Conferenc, AIAA 2005-3336, 2005.

[10] J. M. Hank, J. S. Murphy, and R. C. Mutzman, "The X-51A scramjet engine flight demonstration program," in Proceedings of 15th AIAA International Space Planes and Hypersonic Systems and Technologies Conference, AIAA 2008-2540, Dayton, Ohio, USA, 2008.

[11] V. A. B. Galvão and P. G. P. Toro, "Brazilian 14-X B hypersonic scramjet aerospace vehicle analytical theoretical analysis at mach number 7," in Proceedings of 22nd International Congress of Mechanical Engineering, Ribeirão Preto, Brazil, 2013.

[12] J. R. T. Silva and P. G. P. Toro, "Brazilian 14-X B hypersonic scramjet aerospace vehicle aerothermodynamic code," in Proceedings of 22nd International Congress of Mechanical Engineering, Ribeirão Preto, Brazil, 2011.

[13] P. G. P. Toro, M. A. S. Minucci, J. B. Chanes Jr., A. L. Pereira, and H. T. Nagamatsu, "Development of a new hypersonic shock tunnel facility to investigate electromagnetic energy addition for flow control and basic supersonic combustion," in Proceedings of the 4th International Symposium on Beamed Energy Propulsion, pp. 469-480, Nara, Japan, November 2005.

[14] P. G. P. Toro, M. A. S. Minucci, J. B. Chanes Jr. et al., "New hypersonic shock tunnel at the laboratory of aerothermodynamics and hypersonics Prof. Henry T. Nagamatsu," in Proceedings of 4th International Symposium on Beamed Energy Propulsion, Kailua-Kona, Hawaii, USA, 2007.

[15] D. Romanelli Pinto, T. V. C. Marcos, V. A. B. Galvao et al., "Flow characterization of the T3 hypersonic shock tunnel," in Proceedings of 28th International Symposium on Shock Waves, 2011.

[16] J. A. Anderson Jr., Modern Compressible Flow, The Historical Perspective, McGraw-Hill, The Historical Perspective McGrawHill, Inc., 2nd edition, 1990.

[17] K. Subbarao and J. D. Goss, "Combined magnetohydrodynamic and geometric optimization of a hypersonic inlet," International 
Journal of Aerospace Engineering, vol. 2009, Article ID 793647, pp. 1-12, 2009.

[18] A. F. Moura, A computational stufy of the airflow in scramjet intakes [Dissertation of Master in Sciences In Space and Technology], Instituto Tecnologico de Aeronautica, São José dos Campos, Brazil, 2014.

[19] W. H. Heiser and D. T. Pratt, Institute of Aeronautics and Astronautics, American Institute of Aeronautics and Astronautics, Washington, Wash, USA, 1994.

[20] J. J. Bertin, Hypersonic Aerothermodynamics, American Institute of Aeronautics and Astronautics, Washington, DC, USA, 1994. 


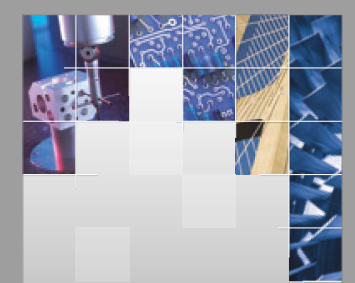

\section{Enfincering}
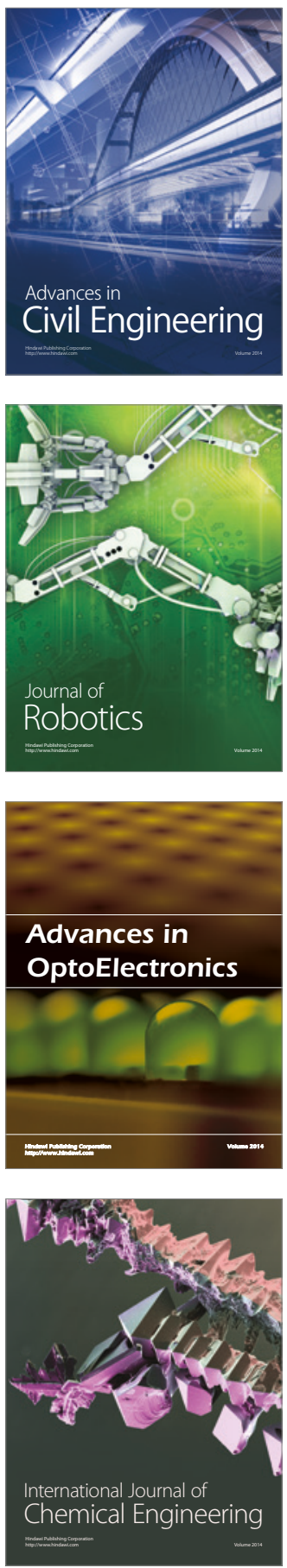

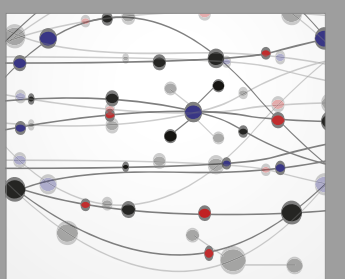

The Scientific World Journal

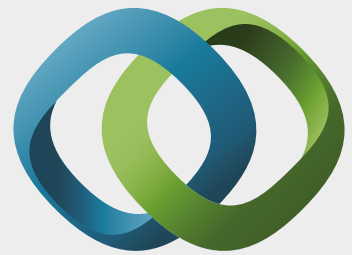

\section{Hindawi}

Submit your manuscripts at

https://www.hindawi.com
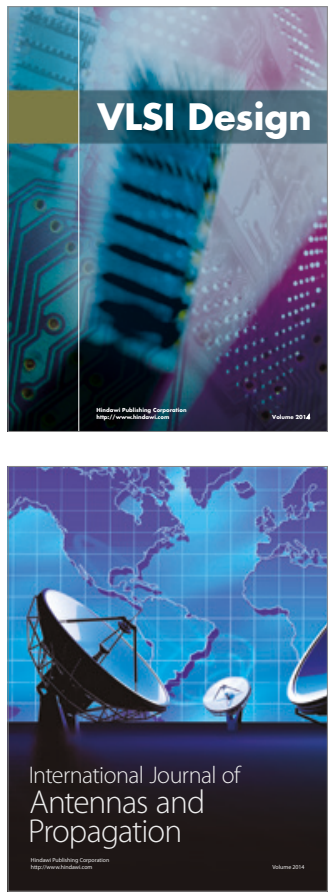

\section{Rotating}

Machinery
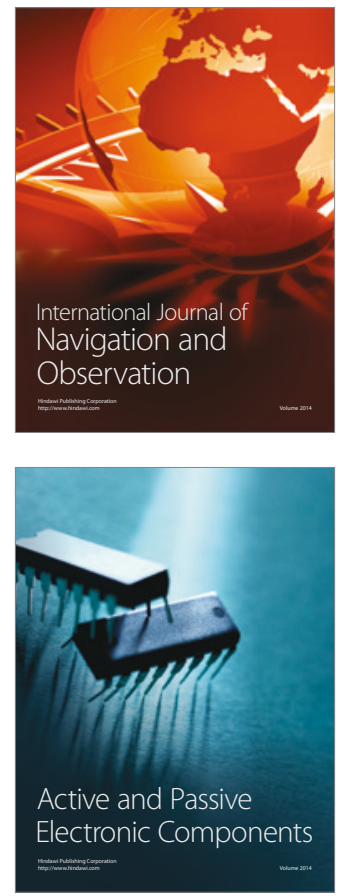
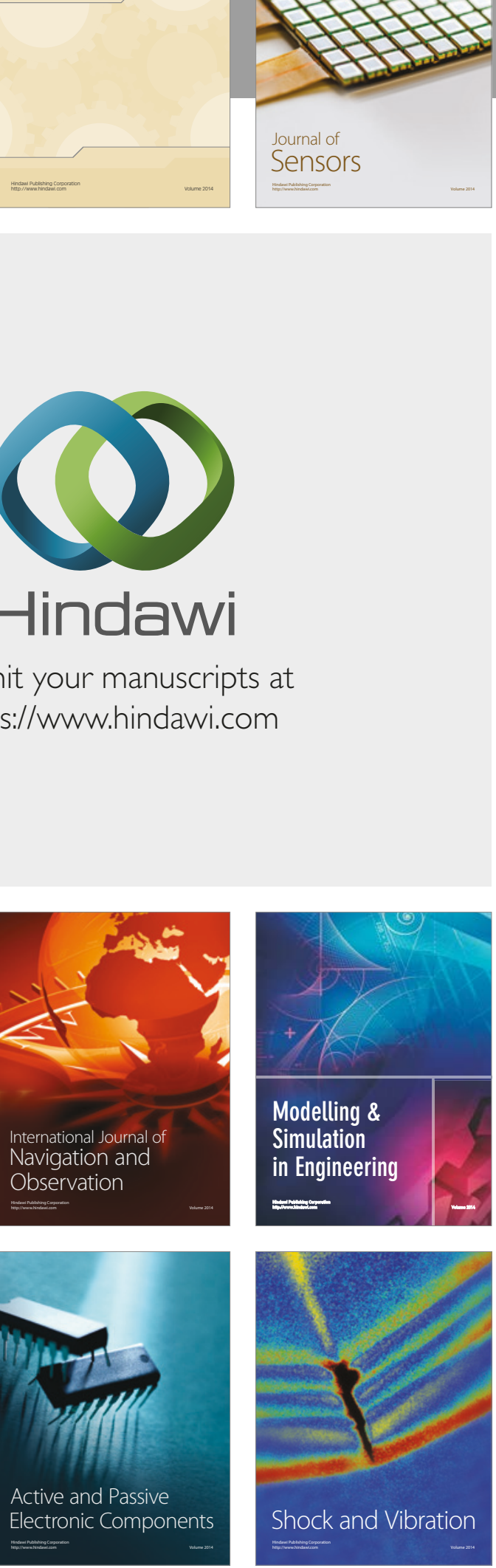
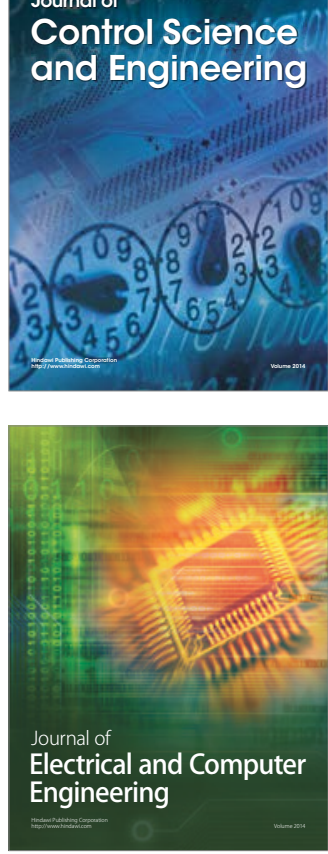

Distributed

Journal of

Control Science

and Engineering
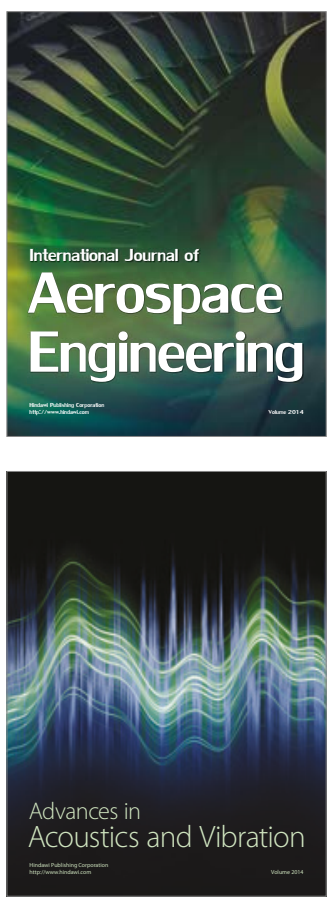

Sensor Networks 